\section{Gender inequities in sexually transmitted infections: implications for HIV infection and control in Lagos State, Nigeria}

\author{
Ezekiel Oluwagbemiga Adeyemi \\ Department of sociology, Lagos State \\ University, Ojo, Lagos, Nigeria
}

\section{Abstract}

Beyond the statistics of sex-based differences in infection rates, there are profound differences in the underlying causes and consequences of HIV infections in male and female which need to be examined. The study therefore examines; the gender differences in the STI knowledge and gender-related potential risks of HIV heterosexual transmission. Quantitative and qualitative data were collected. A multistage random sampling procedure was employed in administration of 1358 questionnaires. For qualitative data, four focus group discussions (FGD) were conducted to collect information from stakeholders within the study population, while In-depth interview was employed to collect information from 188 people living with HIV/AIDS through support groups in the State. The data collected were subjected to basic demographic analytical techniques. Combination of univariate, bivariate, and multivariate analysis were employed. Information from focus group discussions and in-depth interviews were transcribed and organized under broad headings that depict different aspects of the discussions. Majority of the respondents interviewed did not inform their partners about their infection in the study area. It was also discovered that stigmatization did not allow some women to disclose their status to their sexual partners. Some of the HIV-positive patients interviewed agreed that they did not attend the health facilities to treat the STI's before they were finally confirmed positive. The study hypothesis revealed that communication between partners about STI's was associated with an increase in risk reduction behaviour The paper concluded that there is need for more information and education on communication about STI's between the sexual partners; to reduce the spread of sexually transmitted diseases within the nation.

\section{Introduction}

In the developing countries, there has been a changing pattern of male/female HIV infec- tions. ${ }^{1,2}$ Early cases in many countries were concentrated in male homosexuals and intravenous drug users. But as the epidemic continues to spread, there has been a progressive shift towards heterosexual transmission and increasing infection rates among females. The reality today is that, globally, more women than men are now dying of HIV/AIDS, and the age patterns of infection are significantly different for the two sexes. ${ }^{3}$

Beyond the statistics of sex-based differences in infection rates, there are profound differences in the underlying causes and consequences of HIV/AIDS infections in male and female, reflecting differences in biology, sexual behaviour, social attitudes and pressures, economic power and vulnerability ${ }^{4}$ In many ways, the inequity that women and girls suffer as a result of HIV/AIDS serves as a barometer of their general status in society and the discrimination they encounter in all fields, including health, education and employment. Due to their position, African women have difficulty in saying no to sex or to unprotected sex since they are socially and economically dependent on male partners. ${ }^{5}$ Also, due to the limited livelihood opportunities and various forms of gender discrimination and harassment, women adopt sexual survival strategies; they sell their bodies at the work place, or at school, in order to gain access to resources, security, patronage or protection. This may be aggravated, where women lose their livelihood as they become widows through AIDS.

The practice of forcing young girls into marriages sometimes at early ages is not only traumatic, but also devastating. It is difficult to separate the social and physiological causes, especially when young women who are at particular physical risk are exposed to sexual practices over which they have limited control due to social conditions. For social reasons, women tend to have older male partners, the peak age of new infection is between 15 and 25 years, whereas men tend to become infected 5 10 years. $^{6}$

The gender-based norms surrounding sexual behaviour also make the female gender to be more infected than male. Women are thought to leave sexual initiative to men and, or, behave in ways, which please men (e.g. use of virginal stimulants), whilst increasing risk to themselves ${ }^{7}$ They are also expected to limit their sexual relations, often to marriage or long-term partnership, while men are often encouraged to express their masculinity and increase their social status by having many partnerslots of sexual experience, increasing not only their own risk of infection, but also that of their monogamous partners. ${ }^{1,8,9}$ It is for these reasons that HIV/AIDS is inherently a gender-based issue and needs to be seen in this light if it is to be addressed effectively.

That the greatest risk of sexually transmit-
Correspondence: Adeyemi Ezekiel Oluwagbemiga, Department of sociology, Lagos State University, 0jo, Lagos, Nigeria.

E-mail: gbemibolaa@yahoo.com

Key words: HIV/AIDS, STI's not hiv/aids, stis'

Acknowledgement: I thank Council for Development of Social Research in Africa (CODESRIA) for providing the research grant for this work.

Received for publication: 9 July 2009. Accepted for publication: 1 April 2011.

This work is licensed under a Creative Commons Attribution NonCommercial 3.0 License (CC BYNC 3.0).

(C) Copyright Ezekiel O. Adeyemi., 2011

Licensee PAGEPress, Italy

Infectious Disease Reports 2011; 3:e7

doi:10.4081/idr.2011.e7

ted diseases (STDS) and AIDS to women in Africa is provided by their husbands and other unstable partners has long been established. ${ }^{10}$ This is evidently different from infection through homosexual transmission characteristic of the west. The issue of concern and control of the AIDS epidemic in Africa, must therefore necessarily focus on communication about sexual issues (such as condom use, information about STI's and other reproductive matters) between men and women in conjugal or other such intimate relationships. It was observed that the use of personal protection (condoms) against STD risk appeared not to be influenced by concern about HIV and AIDS; rather avoiding pregnancy was found to be the main reason for using condoms. ${ }^{11,12}$ The respondents felt they were not well informed about HIV/AIDS, particularly in the emotional and social aspects of the disease. The majority of the commercial sex workers knew that using condoms protected them from STDs, only onethird were using them regularly. ${ }^{11}$ This has a serious implication for the spread of HIV infection in Nigeria. It can be difficult or impossible for sex workers to insist on safe sex, clients might react with violence or simply move on to someone willing to forego a condom. A study in India found out that clients of the commercial sex workers were willing to pay almost double the fee for sex without a condom. ${ }^{12}$ They observed that young people are putting each other's sexual health at risk because they are too embarrassed to tell their partner they have a sexually transmitted infection (STI). A new NHS survey shows that $16 \%$ of under 25 s would not tell the person that they are sleeping with if they found out they had a STI while $19 \%$ are not sure. Men were found to be much more likely to stay silent about the infection than 
women. $21 \%$ would not tell the person that they are currently sleeping with, while $21 \%$ said they weren't sure.

The trust in partners was reported as a reason for believing a partner could not be HIV positive, regardless of knowledge of their HIV status. Sexual communication has been identified as one of the key components in understanding the interpersonal interactions that facilitate or impede sexual health protective behaviours, including condom use. ${ }^{10}$ Most of the researches in this area has focused on discussions specifically about condom use and the positive health protective implications of such discussions. Numerous studies have shown a direct correlation between communication about condom use and higher rates of actual condom use. ${ }^{13,14}$ Looking at the various implications of non-verbal communications about the sexually transmitted infections especially among partners, effective control of HIV/AIDS requires an understanding of the sexual communication between partners since the major mode of transmission in Nigeria is through heterosexual behaviour. The paper will therefore identify the gender differences in the STI knowledge, gender-related potential risks of HIV heterosexual transmission and the socio-economic and demographic determinants of STIs in the study area. There is need for more information from urban centres, as the present study proposes, due to the availability of commercial sex workers, greater sexual freedom and varies socio-economic changes that have led to a widening of sexual networks in these areas.

\section{Materials and Methods}

\section{Quantitative data}

Data for the study were obtained from one urban, one semi-urban and one rural Local Government Areas (Ikeja, Badagry and Epe Local Government Areas respectively). This is to make the selection representative of the whole state. A multistage cluster sampling technique was used to select respondents for the quantitative data. Using the demarcated enumeration areas ${ }^{15}$ fifty enumeration areas (EAs) were randomly selected from each of the selected local government areas. From each EA, systematic random sampling technique was used to select ten houses and one household per housing unit was selected for the survey. In each of the selected household, lottery method was used to select a male and a female of reproductive age (15-49 years) that were interviewed.

Sample selection was done using EPI INFO Version 6 STATCALC $^{16}$ given as $\mathrm{S}=\mathrm{Z}^{*} \mathrm{Z}$ (P (1$\mathrm{P}) /\left(\mathrm{D}^{*} \mathrm{D}\right)$, in which $\mathrm{D}$ is one half the width of the desired sample confidence interval. $\mathrm{Z}$ is a Percentile of the standard normal distribution determined by the specified confidence level ( 1.96 for $5 \%$ confidence level). $\mathrm{S}$ is then adjusted by a finite population correction factor to obtain the final estimate of sample size as, follows: Sample Size $=\mathrm{S} /(1+\mathrm{S} /$ population (These equations were written for the software by CDC).

From this information, the following sample sizes were derived for each of the local governments (Table 1). The sample size envisaged was not actualised because of the time constraints and non responses of some of the respondents selected. This excludes PLWHA in the study area.

However, quantitative method preceded the qualitative in order that the survey results could be interpreted and investigated in more in depth using interviewing techniques. For quantitative data, questionnaire was used to collect information from the general populace this does not include the PLWHA. The purpose is to develop understanding of how the undisclosed STI's status may be contacted by other partners. The questionnaire for the survey was designed to elicit information relating to the objectives of the study. The questionnaire was divided into sections including; background characteristics, sexual relations with partners other than spouses, STDs and health issues, communication about STI's, Treatment seeking behaviour, AIDS awareness and knowledge, stigma and discrimination. Returned questionnaires were subjected to thorough screening, checking for consistency and finally edited. The data collected were subjected to basic demographic analytical techniques. In the statistical analysis of the data, a combination of univariate, bivariate, and multivariate analysis were employed. The logistics regression technique was used to test formulated hypotheses and the pattern of relationship between the dependent and independent variables. (e.g. ever contracted STIs, had STIs=0 no=1) and other independent variables (such as income, education, occupation, negative attitudes, age at first intercourse, perceived risk of infection, concurrent partner, knowledge about, STI).

\section{Qualitative data}

Different approaches were used for people leaving with HIV/AIDS since research in HIV/AIDS infection is unlike any ordinary phenomenon in Demography, due to the stigma and discrimination attached to the disease. Even at the best of times, demographic data are affected by distortions and misinformation. ${ }^{17,18}$ AIDS is a disease whose sufferers have been stigmatised and blamed for the out break and the spread. ${ }^{14}$ Therefore, patients who agreed to be interviewed could be considered as those motivated enough to share their experiences with others. ${ }^{19,20}$ A related issue in AIDS research is ensuring confidentiality. Thus, in dealing with AIDS patients, it is not possible to obtain a representative sample as is normally done in population studies. Due to this, purposive sampling technique was used. People Living with HIV/AIDS (PLWHA) were identified through the help of some organizations, the support groups that are dealing directly with people living with HIV/AIDS (PLWHA). These organisations were reached through the Family Health International (FHI) Lagos, an international Non-Governmental Organisation. The consent of each of the interviewee was sought by filling a consent form before the interview. The researcher also employed the service of one HIV/AIDS counsellor who counselled each of the respondents interviewed. From these organisations, one-hundred and eighty-eight (188) PLWHA were interviewed. Four focus group discussions were also conducted among males and females in the study population (2 males and 2 females). The information collected from focus group discussions and In-depth interviews are raw data. These were transcribed verbatim. This provides a complete record of the discussion and facilitates analysis of the data. The content of the discussion was analyzed and organized under different headings that depict different aspect of the discussions. The aim of this analysis is to look for trends and patterns that reappear within either a single focus group or among the focus groups or within the in-depth interviews.

Table 1. Summary profile of sample size and actual number of respondents.

\begin{tabular}{lccccc}
$\begin{array}{l}\text { LGAs } \\
\text { selected }\end{array}$ & $\begin{array}{c}\text { Population } \\
\text { Sample } \\
\text { sive } \\
\text { envisaged }\end{array}$ & $\begin{array}{c}\text { Actual number of respondent interviewed } \\
\text { Male }\end{array}$ & $\begin{array}{c}\text { Female } \\
\text { Iotal }\end{array}$ \\
Ikeja & 326,512 & 534 & 269 & 230 & 499 \\
Badagry & 191,472 & 472 & 250 & 201 & 451 \\
\hline Epe & 162,891 & 415 & 212 & 196 & 408 \\
Total & & 1421 & 731 & 627 & 1358 \\
\hline
\end{tabular}




\section{Results}

\section{Socio-demographic characteristics}

From Table 2, the age pattern of the respondents indicated the proportion of respondents in age group 15-24years and 35-44 years are small for male and female respondents respectively. This implies that majority of the sample population are in the economic active group. It is also a true picture of population with high fertility. Half of the male respondents are married, while only 38 percent of the female respondents are married. More females indicated that they are divorcees (21.9 percent). This observation reflects the effect of polygyny which is widely practiced in many parts of the country and differences in age at marriage between spouses. Forty-one percent of the female respondents reported that their husband have other wives, while $58.7 \%$ reported monogamous unions. The reason for the different pattern observed may be the impact of the urbanization and modernization in the study area.

The education pattern shows that 91 percent of the population and 81.5 percent of male had received formal education. The distribution of the respondents by religion shows that three out of every five are Christians, while only 1.9 percent are adherents of African traditional religion. In is interesting to know that $48.2 \%$ of the women were Muslims, compared to only $29.2 \%$ of the men. The reason could not be farfetched that Muslim women were more likely to be at home than men. Two-thirds of the female respondents are living below the UN standard of US dollar \$1 per day. This will influence their reproductive decision- making especially with the ability to say no to sex and the use of contraceptive. More than half of the respondents are employed in trading services, regardless of sexes. A slightly higher proportion of females compared to male respondents (21.5\% and $18.5 \%$ respectively) are in civil /public service. Twelve percent of male respondents are professionals compared with female respondents, which is less than five percent. This reveals the gender gap in education in Nigeria, where more males are in professional courses in the higher institutions than their female counterparts. Eight percent of the female respondents are full-time house wives who depend on their husbands for survival. Such women may not be able to take reproductive decisions without the consent of their husbands.

\section{Extramarital sexual relations}

From Table 3, more than two- thirds of the male respondents and half of the female respondents had extramarital sex in the last twelve months. This shows that heterosexual relationship is high in the study area. This

Table 2. Socio-demographic characteristics of respondents.

$\begin{array}{ccc} & \text { Sex Composition } & \\ \text { Male } & \text { Female } & \text { Tota } \\ (\mathrm{N}=731) & (\mathrm{N}=627) & (\mathrm{N}=1358)\end{array}$

Age

\begin{tabular}{lccc}
$15-24$ & 10.0 & 22.3 & 15.7 \\
$25-34$ & 35.4 & 55.6 & 44.7 \\
$35-44$ & 19.4 & 1.1 & 11 \\
$45+$ & 35.2 & 20.9 & 28.6 \\
Total & 100.0 & 100.0 & 100.0 \\
Marital status & & & \\
Single & 36.9 & 18.8 & 28.3 \\
Married & 55.4 & 38.1 & 47.5 \\
Divorced & 7.7 & 21.9 & 14.2 \\
Widow/Widower & - & 21.2 & - \\
Total & 100.0 & 100.0 & 100.0 \\
\hline
\end{tabular}

Husband having other wives

$\begin{array}{lll}\text { Yes } & - & 41.3\end{array}$

$\begin{array}{lll}\text { No } & - & 58.7\end{array}$

Total - $\quad 100.0$

\begin{tabular}{lccc} 
Ethnic group & & & \\
Yoruba & 44.6 & 75.4 & 57.7 \\
Ibo & 26.1 & 24.4 & 25.4 \\
Hausa/Fulani & 10.8 & 0.2 & 6.3 \\
Others & 18.5 & - & 10.6 \\
Total & 100 & 100 & 100 \\
\hline
\end{tabular}

Religion

\begin{tabular}{lccc} 
Christianity & 69.6 & 49.1 & 60.2 \\
Islam & 29.1 & 48.2 & 37.9 \\
Traditional & 0.2 & 2.7 & 1.9 \\
Total & 100 & 100 & 100 \\
Education & & & \\
None & 18.5 & 19.3 & 21.1 \\
Primary & 15.0 & 28.1 & 26.2 \\
Secondary & 29.3 & 26.8 & 20.9 \\
Post Secondary & 37.2 & 25.4 & 31.8 \\
Total & 100.0 & 100.0 & 100.0 \\
\hline
\end{tabular}

Occupation

$\begin{array}{lll}\text { None } & - & 8.0\end{array}$

$\begin{array}{llll}\text { Trading } & 55.8 & 55.0 & 55.4\end{array}$

$\begin{array}{lll}\text { PubliclCivil Servant } & 18.5 & 21.5\end{array}$

$\begin{array}{llll}\text { Artisans } & 12.9 & 10.6 & 11.8\end{array}$

$\begin{array}{llll}\text { Professionals } & 12.9 & 4.8 & 9.2\end{array}$

$\begin{array}{lll}\text { Total } & 100.0 & 100.0\end{array}$

Income per Annum
$<\mathrm{N} 120,000$

$\begin{array}{llll}<\mathrm{N} 121,000-\mathrm{N} 240,000 & 55.8 & 63.0 & 14.0 \\ & 18.5 & 21.5 & 11.8\end{array}$

$\begin{array}{lll}\text { N241- 360,000 } & 12.9 & 10.6\end{array}$

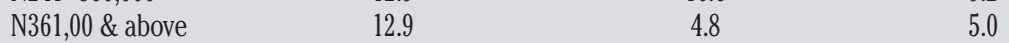

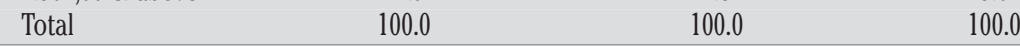

Had Sex in the last 12 months

\begin{tabular}{lccc} 
Yes & 64.6 & 47.2 & 55.6 \\
No & 35.4 & 52.8 & 44.4 \\
Total & 100 & 100 & 100 \\
\hline
\end{tabular}

Source: author's field survey. 
finding is not new and is expected because it corroborates some previous studies that there is high extramarital sexual activity in urban centres in Nigeria, especially Lagos. Despite the fact that AIDS awareness is high in urban Nigeria, a substantial number of people still engage in high-risk sexual behaviour by continuing to have casual sex, or by having multiple partners, without using condom due poor economic situations in the country.

\section{Knowledge of Sexually Transmitted Infections}

In this study, Knowledge of sexually transmitted infections is universal among male and female respondents. From Table 4, all the respondents have heard of STIs before. Besides HIV, the STI's that women were most likely to be familiar with was syphilis, while gonorrhea is the widely known for male respondents. Although gonorrhea is the most widely known sexually transmitted infection among women, Herpes and Candidiasis follow next among men in the study area.

The major source of their information is through the media, television and radio, while other sources are, friends (male $32.1 \%$, female $36.8 \%$ ) and Hospital (male 30.7\%, female 19.6\%). Correct STI symptoms for male and female were considered to be: abdominal pain, blood in urine, burning pain with urination, discharge from vaginal or penis, failure to pass urine, genital ulcers or open sores, inability to conceive, itching in the genital area, loss of weight, pelvic pain during intercourse, and swellings in the genital area.

The percentage of female respondents who reported that they contracted sexually transmitted disease $(86.5 \%)$ is higher than male (36.9\%). In all this (59\%) indicated they had had STI's in the past twelve months preceding the survey, this is very high incidence which may also have implications on the reproductive health of the respondents Eighty-five percent of all the male respondents who indicated that they contacted STIs revealed they knew their status through medical examinations, while half of the female respondents knew their STIs status through itching of the private parts and other symptoms. This was also supported by the responses from the FGDs discussants.

A female discussant:

It was a few months ago I started noticing some smelling discharge from my private part. I then contacted a medical doctor who diagnonised me and told me it was sexually transmitted infection that resulted to the discharge

A male discussant:

It was one day when I wanted to urinate that I discovered there were traces of blood in my urine and it was my friend who told me that it was gonorrhea.
Table 3. Distribution of gender differences in STI Knowledge.

\begin{tabular}{|c|c|c|c|}
\hline & $\begin{array}{c}\text { Male } \\
(\mathrm{N}=731)\end{array}$ & $\begin{array}{c}\text { Female } \\
(\mathrm{N}=627)\end{array}$ & $\begin{array}{c}\text { Tota } \\
(\mathrm{N}=1358)\end{array}$ \\
\hline \multicolumn{4}{|l|}{ Heard of STIs } \\
\hline Yes & 100.0 & 100.0 & 100.0 \\
\hline No & - & - & - \\
\hline Total & 100.0 & 100.0 & 100.0 \\
\hline \multicolumn{4}{|l|}{ ** STIs Heard of } \\
\hline Gonorrhea & 81.5 & 82.6 & 80.0 \\
\hline Syphilis & 44.6 & 86.3 & 59.9 \\
\hline HIV/AIDS & 100 & 100 & 98.6 \\
\hline Herpes & 55.4 & 81.5 & 68.6 \\
\hline Candiasis & 55.4 & 80.5 & 68.6 \\
\hline \multicolumn{4}{|l|}{ ** Symptoms of STIs } \\
\hline Abdominal pain, & 30.1 & 30.2 & 30.0 \\
\hline Blood in urine, & 25.4 & 28.9 & 26.4 \\
\hline Burning pain with urination, & 28.9 & 45.2 & 35.3 \\
\hline Discharge from vaginal or penis, & 27.6 & 23.5 & 24.5 \\
\hline Failure to pass urine, & 35.8 & 25.7 & 29.4 \\
\hline Inability to conceive, & 25.2 & 25.1 & 25.0 \\
\hline Itching in the genital area, & 45.8 & 45.7 & 45.0 \\
\hline Loss of weight, & 24.8 & 28.4 & 25.3 \\
\hline Pelvic pain during & 32.5 & 05. & 19.4 \\
\hline Swellings in the genital area. & 54.2 & 35.2 & 46.7 \\
\hline Genital ulcers or open sores, & 56.4 & 35.8 & 42.3 \\
\hline \multicolumn{4}{|l|}{ ** Sources } \\
\hline Television/Radio & 59.5 & 37.5 & 49.3 \\
\hline Friends & 32.1 & 36.8 & 34.3 \\
\hline Health centre/Hospital & 30.7 & 19.6 & 22.0 \\
\hline \multicolumn{4}{|l|}{ Contracted STIs } \\
\hline Yes & 36.9 & 86.5 & 58.6 \\
\hline No & 63.1 & 13.5 & 40.0 \\
\hline Total & 100.0 & 100.0 & 100.0 \\
\hline \multicolumn{4}{|l|}{ *How do you know } \\
\hline Through medical examination & $85.2(230)$ & $5.6(24)$ & $36.3(254)$ \\
\hline Inching & $4.4(12)$ & $62.7(270)$ & $40.3(282)$ \\
\hline Vaginal or Penis discharge & $10.4(28)$ & - & $4.0(28)$ \\
\hline Burning pain with urination & - & $31.7(136)$ & $19.4(136)$ \\
\hline Total & $100.0(270)$ & $100.0(430)$ & $100.0(700)$ \\
\hline \multicolumn{4}{|l|}{ Did you seek treatment? } \\
\hline Yes & 90.3 & 78.3 & 79.4 \\
\hline No & 9.7 & 26.2 & 20.6 \\
\hline
\end{tabular}

Source: author's field survey. Multiple response are allowed, excluding non response category.

Table 4. Percentage distribution of gender-related potential risk of HIV heterosexual transmission.

\begin{tabular}{|c|c|c|c|}
\hline Variable & $\begin{array}{c}\text { Male } \\
(\mathrm{N}=731)\end{array}$ & $\begin{array}{l}\text { Female } \\
(\mathrm{N}=627)\end{array}$ & $\begin{array}{c}\text { Total } \\
(\mathrm{N}=1358)\end{array}$ \\
\hline $\begin{array}{l}\text { Did you tell your spouse? } \\
\text { Yes }\end{array}$ & 44.5 & 22.3 & 39.0 \\
\hline $\begin{array}{l}\text { What is your partner's reaction } \\
\text { Put the blame on me } \\
\text { Dejected } \\
\text { Abandon me }\end{array}$ & $\begin{array}{c}14.6 \\
20.4 \\
9.5\end{array}$ & $\begin{array}{c}10.5 \\
0.4 \\
11.3\end{array}$ & $\begin{array}{l}11.4 \\
19.3 \\
10.3\end{array}$ \\
\hline $\begin{array}{l}\text { No response } \\
\text { Total }\end{array}$ & $\begin{array}{r}55.5 \\
100\end{array}$ & $\begin{array}{l}77.8 \\
100\end{array}$ & $\begin{array}{l}65.0 \\
100\end{array}$ \\
\hline $\begin{array}{l}\text { * Did you do anything to prevent it } ? \\
\text { Yes } \\
\text { No } \\
\text { Total } \\
\end{array}$ & $\begin{array}{c}64.9(157) \\
35.1(85) \\
100(467)\end{array}$ & $\begin{array}{l}16.1(75) \\
83.9(391) \\
100(709)\end{array}$ & $\begin{array}{l}38.9(232) \\
61.1(476)\end{array}$ \\
\hline $\begin{array}{l}\text { What did you? } \\
\text { Use Condom } \\
\text { Abstain from sex } \\
\text { Others } \\
\text { Total }\end{array}$ & $\begin{array}{c}56.7(157) \\
43.3(157) \\
- \\
100\end{array}$ & $\begin{array}{c}66.0(75) \\
32.7(75) \\
1.3 \quad(75) \\
100\end{array}$ & $\begin{array}{c}59.9(232) \\
40.5(232) \\
0.6(75) \\
100\end{array}$ \\
\hline
\end{tabular}

Source: author's field survey. *these are those who noticed STI symptoms. 


\section{Treatment seeking behaviour of STIs}

Ninety percent of males and $78 \%$ of female respondents sought treatment. The high rate in number $(79.4 \%)$ of respondents seeking treatment may not be unconnected with the level of awareness of STIs and the influence of urbanization in the study area and availability and access to medical services. The differences between male and female in terms of seeking treatment may be related to the stigma attached to these STIs. To many people, it shows that the woman is not faithful to her husband. This can make the woman unwilling to disclose her STI status and seek treatment.

A female discussant: When I first noticed the sign of STDs, I was told that it was gonorrhea. Since I did not have any other man except my husband. I told him about this. Instead of admitting that I contacted the disease from him, he accused me of unfaithfulness in our marriage. A 35 years old woman: When I noticed the sign of STDs I did not disclose it to anybody except the traditional healer. It was after a month that my husband complained to me about the similar symptoms. He accused me of infidelity in our marriage.

Women with sexually transmitted infections are more likely to be asymptomatic and therefore less likely to seek treatment The consequences of undetected and untreated STIs are devastating and these include: HIV, infertility, ectopic pregnancy, miscarriage, social stigmatization and premature death imposing huge economic and social burden on the family. This was confirmed from the in-depth interview among the People Living With HIV/AIDS in the State.

An illiterate male discussant: Nigbati mo ni arun gbajumo mofi lo ore mi . Osi mu mi lo si odo awon Oloogun ibile won si fun mi ni ogun

Lehin igba die olo sugbo otun pada wa. Ki to wa losi ile iwosan fun itoju nigbati mi o fe gbadun mo - When I had gonorrhea, I told a friend of mine and he took me to a native doctor who gave me medicine. After a while, I was relieved but the symptoms resurfaced. It was then I went to the hospital for treatment before I was later confirmed HIV positive.

The majority of those who sought treatment among the respondents did so in the government hospitals, while seven percent of female respondents sought treatment from traditional healers. Reasons given by respondents for not visiting the health facilities is the stigma attached to it that it can only be contracted through immoral acts. This prevents some of them from visiting the clinics even when they already knew that they are infected. They may be too embarrassed or feel guilty to seek treatment. Service may also be inaccessible because clinics may be far away from them.

\section{Gender-related potential risk of} HIV heterosexual transmission

From Table 4, 22 percent of the female respondents, and 44 percent of the male respondents informed their partners about their infections. For instance a 30 year- old full-time housewife says: There is no way I can inform him about the STIs and ask him to use condom to prevent him from contracting it. My husband will beat me. Even he would not use condom from preventing the next pregnancy. If I insisted he will not give us money for food. A 25 year old lady: Even when you inform men that they should use condom, that you are infected with STI's they will still insist on unprotected sex.

Surprisingly, majority of the female respondents did not do anything to prevent the infection from being contracted by the sex partner (Table 6). This shows that there is the likelihood of transmitting the infection to their partners. Women also do not have the courage to tell their husbands to use condom.

Sixty-six percent of females and $56 \%$ males used condom, while more males (43.3\%) than females (32.7\%) abstain from sex. The Study

Table 5. Bivariate analysis of some socio-economic characteristics of respondents by ever contracted STI's.

\begin{tabular}{|c|c|c|c|c|c|c|}
\hline \multirow[t]{2}{*}{ Variable } & \multicolumn{3}{|c|}{ Male } & \multicolumn{3}{|c|}{ Female } \\
\hline & Yes & No & Total & Yes & No & Total \\
\hline \multicolumn{7}{|l|}{ Age } \\
\hline $15-24 Y r s$ & $8.2(6)$ & $91.8(67)$ & $100(73)$ & $96.4(134)$ & $5.6(6)$ & $100(140)$ \\
\hline 25-34Yrs & $0.8(2)$ & $99.2(257)$ & $100(259)$ & 76.8 (255) & $24.2(94)$ & $100(349)$ \\
\hline \multirow[t]{2}{*}{35 and Above } & $65.7(262)$ & $34.3(77)$ & $100(339)$ & 100 (137) & & 100 (137) \\
\hline & & $\mathrm{X}^{2} \mathrm{P}=0.019$ & & & $\mathrm{X}^{2} \mathrm{P}=0.14$ & \\
\hline \multicolumn{7}{|l|}{ Marital status } \\
\hline Single & - & - & & $98.3(115)$ & $1.7(3)$ & $100(118)$ \\
\hline Married & $66.7(270)$ & $32.3135)$ & $100(405)$ & 95.8 (228) & $4.2(11)$ & $100(239)$ \\
\hline Divorced & & & & $41.2(56)$ & $58.8(81)$ & 100 (137) \\
\hline Widow/Widower & - & & & 100 (118) & -2 & 100 (118) \\
\hline \multicolumn{7}{|l|}{ Education } \\
\hline None & $69.1(76)$ & $31(59)$ & $100(135)$ & $60.0(105)$ & $30.0(15)$ & 100 (118) \\
\hline Primary & $36.9(79)$ & $63.1(31)$ & $100(105)$ & $94.0(166)$ & $6.0(10)$ & $100(176)$ \\
\hline Secondary & - & $100(214)$ & $100(214)$ & $64.3(108)$ & $35.7(60)$ & 100 (168) \\
\hline Post secondary & $42.2(115)$ & $57.8(157)$ & $100(272)$ & $90.7(147)$ & . & $100(162)$ \\
\hline \multicolumn{7}{|l|}{ Income } \\
\hline$<\mathrm{N120,000}$ & 37.9 (104) & $62.1(170)$ & $100(274)$ & 90.6 (204) & $9.4(21)$ & $100(225)$ \\
\hline $121,000-240,000$ & $37.5(93)$ & $62.5(155)$ & $100(248)$ & $16.9(42)$ & $83.1(162)$ & $100(204)$ \\
\hline N241 \& Above & $34.9(73)$ & $65.1(136)$ & $100(209)$ & 14.9 (38) & $85.1(160)$ & 100 (198) \\
\hline
\end{tabular}

Table 6. Association between communication and risk reduction behaviour.

\begin{tabular}{lcc} 
Variable & Male & Female \\
*Did you do anything to prevent it ? & & \\
Yes & 65.3 & 72.3 \\
No & 34.7 & 27.7 \\
$X^{2}$ P value What did you? & $\mathrm{X}^{2} \mathrm{P}=0.032$ & $\mathrm{X}^{2} \mathrm{P}=0.421$ \\
Use condom & 50.2 & 34.5 \\
Abstain from sex & 35.5 & 55.3 \\
Others & 14.3 & 10.2 \\
$\mathrm{X}^{2} \mathrm{P}$ Value & $\mathrm{X}^{2} \mathrm{P}=0.02532$ & $\mathrm{X}^{2} \mathrm{P}=0.0421^{*}$ \\
\hline
\end{tabular}

revealed that even though the partners were informed about the infections, females do not have the unilateral power or decision to abstain from sex unless their husbands cooperated.

Bivariate analysis of socio-economic characteristics of respondents and ever contracted STI's

From Table $5,96.4 \%$ of female and $8.25 \%$ of male respondents have contracted STIs. This shows that young females are more at risk of contracting STIs since most of them are less likely to use condom and they are involved in risk behaviourNinety-eight percent of the female respondents who are single have contracted STIs while the highest number of these are those who are widows and the least are those who are divorced. On the other hand, 66.7 percent of those married men have contracted STIs, and this shows that there are considerable extramarital relationships among both sexes in the study area.

Two-thirds of male respondents who do not have education contracted STIs, while the least are those with primary education. The pattern 
among the female respondents was different from the male respondents. Ninety-four percent of female respondents with primary education have contracted STIs while the least are those with no education (60\%). This is an indication that women are highly vulnerable to STIs, regardless of their level of education. This may be largely cultural as women are not supposed to decide for their partners as to whether to use condom. Power inequalities lead women to acquiesce to non -condom use, even when they are convinced that their partner should use it.

The pattern of income among the female respondents depicts that there is inverse relationship between level of income and ever contacted STI's in the study area. Many women are economically dependent on men; hence the degree to which they are able to express their own will is often limited. This lack of choice, or lack of economic power, leads some women to engage in high-risk behaviours, which increase their chance of contracting the HIV virus. This finding was supported by the discussants from the focus group discussion: i) A female discussant: Since majority of the women depend on their husbands, there is no way they can say no to sex. Even when they are aware that their husbands are infected with STI's. The man or the husband will deny them money and other benefits. It is only those that have good business or job can say no to "sex" when their husbands are infected; ii) A business woman: It is a lazy woman, who cannot say no to unprotected sex when her husband is infected with STI's.

\section{Multivariate analysis of selected independent variables and depend- ent variables}

The multivariate analysis was employed to explore the relationship between socio-economic characteristics of respondents and Sexually Transmitted Infections. It will show the effect of background on ever contracted STI's. From Table 7 the age pattern of the respondents shows that people in the younger age bracket are likely to be infected with STI's than those in the older ages in the study area. Those in the age group of 15-24 years and 2534 years are 2.367 and 2.475 times as likely to have STI's than age group 45 years and above the reference category in the study area. Income has been established as a factor influencing premarital and extramarital relationship, from the logistic regression, those in higher income between N121,000-N240,000 are 5.3 times likely to have STI's than those with the lower income, while those in $\mathrm{N} 241,000$ and above are 1.2 times likely to have STI's. Men in this category would have the means or resources to attract women with lower socio-economic status especially young females. The occupation follows the pattern of education, those with good jobs especially professionals, are 1.3 times as likely to have STI's when compared with the reference category (which is those that did not have job). These are the people that are also with high income and have the means to attract females into sexual relationships. The model also revealed that those who did not prevent the transmission of STI's are 1.12 times likely to contact STI's when compared with those who prevent transmission either by using condom or abstain from sex.

\section{Discussion and Conclusion}

Misconceptions about the implications of STI's can act as hindrances to behaviour change. The study shows that majority of the sexual partners that are infected did not reveal their status to their partners. In some cases their partners are also infected. The study shows a positive relationship with communication and risk reduction in the study area. Those who informed their partners may likely to prevent infection and re-infection. Stigma attached to STI's did not allow women to reveal their status to their sexual partners. The study confirms that people who are infected with STIs are more likely to get HIV if exposed to it through sexual contact and also are more likely to transmit HIV.

A female discussant said: When I noticed some smelling discharge I consulted a chemist who gave me some drugs and it disappeared before I later tested positive. An Igbo woman: My husband felt sick and the ailment was so severe that we took him to the village to see native doctor but he eventually died. After few months of mourning, I started feeling the same way as my husband (discharges from my private parts, rashes on my body, sore in my tongue) and my sister took me to the hospital. They did the test for me and it was positive. It was then I knew that my husband died of the disease. $^{21}$

They explained that health problems from STDs tend to be more severe and more frequent in women without early symptoms and they may have delay in getting care. It was also discovered that gender imbalances in sexual relationship did not allow women to have the confidence in challenging their partners and this eventually leads to infection and reinfection of sexually transmitted diseases. The study reveals that sexually transmitted infections are higher among the female adolescents because they are more likely to have many irregular sexual partners without adequate protection from infections. It was reported that STI's rates are high in among adolescents in Nigeria. He explained that some people who
Table 7. Logistic regression of model to identify the socio-economic determinants of STI.

\begin{tabular}{lc}
\hline Variables & Odd ratio \\
Age & \\
15-24 Years & 1.4882 \\
25-34 Years & 1.4138 \\
35-44 Years & $1.12^{*}$ \\
45 \& above & $\mathrm{RC}$ \\
Marital Status & \\
Single & $2.48^{*}$ \\
Married & $2.56^{*}$ \\
Divorced & 1.22 \\
Widow/Widower & $\mathrm{RC}$ \\
\hline Occupation & \\
None & $\mathrm{RC}$ \\
Trading & 1.02 \\
PubliclCivil Servant & 1.02 \\
Artisans & $2.81^{*}$ \\
Professionals & 3.95 \\
Income & \\
$<$ N120,000 & \\
121,000-240,000 & \\
N241 \& Above & \\
Prevent Transmission & \\
Yes & \\
No & $\mathrm{RC}$ \\
\hline
\end{tabular}

Source: author's field survey . RC indicates the reference category. ${ }^{*}$ Sig. at $\mathrm{P}<.05$. ** Sig. at $\mathrm{P}<.01$

wish to abstain from sex or who might want to protect themselves with condoms during sex are unable to do so because of economic circumstances and gender inequality. ${ }^{22,23}$ Many young women find themselves in a position where engaging in sexual relations is one of their few available survival strategies

Adolescents are particularly vulnerable because they are more likely to have multiple partners and less likely to prevent, or recognize, STIs. ${ }^{23}$ Among heterosexual adolescents, STD rates are higher for females than males, possibly because females are more likely to acquire an STD following a single act of unprotected intercourse with an infected partner.

After finishing my secondary school and I did not pass my 0 level examination, my friend just came home and told me to join her in Lagos to come and do business so that I can have money for my examination. On getting to Lagos, I was told that I will make my money by what I have (i.e. my body) Eventually I joined her as a commercial sex worker, early this year I was confirmed positive.

The income patterns show that women who are economically empowered are less likely to contact STI's and are able to say no sex when their husbands are infected. People with post secondary education are 5.0 times as likely to have STI's when compared with those that did not have job. It shows that education of the respondents did not have impact on the STI's.

However, since condom is the only contraceptive method that clearly prevents transmis- 
sion of STIs, the AIDS epidemic has brought urgency and new attention to issues of condom use involving trust, negotiation, and communication between sex partners. For most of the female respondents, asking an intimate partner to use a condom suggests a lack of trust, particularly in a long-term relationship, requesting the use of condoms could imply distrust rather than caring. Even when a person knows or suspects infidelity, she or he still may not ask to use condoms because maintaining the marital relationship seems more important than avoiding the risk of future health consequences. More males used condoms when compared with females after informing their partners about their STI's status. Communication between sexual partners is important with regard to sexually transmitted infections in order to prevent infection and reinfection between them. Women often have little control over the mode of sexual relations or the behaviours of their partners. Gender issues, such as power imbalances in sexual relationships, may interfere with condom use and may prevent women from protecting themselves, even if they are aware that their partners' behaviour may be putting them at risk. ${ }^{24,25}$

People need to learn to talk about sex directly. While some couples discuss sex and cooperate in making the decision to use condoms, much communication is indirect. Most people learn about their partner's sexual needs from a combination of hints and nonverbal body language rather than from direct communication. Non-verbal communication indirectly, however, leaves more room for misinterpretation than does talking. Non-talkers face greater risk for STIs than talkers because their lack of communication often prevents effective preventive behavior - especially behavior that requires cooperation, such as condom use. ${ }^{26}$

In conclusion, since programmes and research on HIV/AIDS are currently undergoing a shift from focus on the risk groups to men. The clamour now is to change the behavioural attitudes of men to safer sex. There is need for more information and education on communication about STI's between the sexu- al partners; this will reduce the spread of sexually transmitted diseases within the nation. People should be educated about the need to receive appropriate treatment when noticing any symptoms of STI's.

\section{References}

1. Durrant V. Impact of AIDS on Women in Uganda. East Lamsung:Michigan State University. Office of Women in International Development. 1994;249.

2. UNAIDS. 2007 AIDS epidemic update. 2007. Available from: data.unaids.org/ pub/epislides/2007/2007_epiupdate_en.pf

3. UNAIDS. World AIDS Report 2004. 2004.

4. Matlin S, Spence N. The Gender Aspect of the HIV/AIDS pandemic. Expert Group meetings on "The HIV/AIDS pandemic and its Gender Implications" 2000. Available from:http://www.un.org/womenwatch/daw/ csw/hivaids/matlinspence.html

5. Orubuloye IO, Caldwell P, Caldwell J. The role of high risk occupation in the spread of AIDS: truck drivers and itinerant market women in Nigeria. Inter Fam Plan Perspect 1993;19:43-8.

6. World Health Organisation. AIDS Statistics 2002.

7. George A, Jaswal S. Understanding sexuality: An ethnographic study of poor women in Bombay. International Centre for Research on Women and AIDS Programme Research 1995.

8. Mason KO. HIV transmission and the balance of power between women and men: A global view. Health Transit Rev 1994:21740.

9. Rogo K0. Induced Abortion in subSaharan Africa. East Afr Med J 1993;70: 386-95.

10. Frank 0. Infertility in Sub-Saharan African: estimates and Implications. Pop Dev Rev 1983;9:137-44.

11. Orubuloye IO, Oguntimehin F. Interven- tion for the control of STDs including HIV among commercial sex workers and students in Nigeria. Health Trans Rev 1999;121-9.

12. UNAIDS. World AIDS Reports 2002. 2002.

13. Hiller L, Harrison L, Ware D. When you carry condom all the boys think you want it: Negotiatng competing discourses about safe sex. J Adol 1998;21:15-29.

14. Sheeran P, Abraham C, Orbell S. Psychosocial Correlates of heterosexual condom use: A meta-analysis. Psychol Bull 1999;125:90-132.

15. National Population Commission. 2006 Population Census Figures Abuja.

16. Centre for Disease Control. EPI-INFO 2000 USA.

17. Bleek W. Avoiding shame: the ethical context of abortion in Ghana. Anthro Quart 1981;54:203-9.

18. Bleek W. Lying informants: a fieldwork experience from Ghana. Pop Dev 1987;13: 314-22.

19. World Health Organisation: Women's health in South-East Asia Report 2002.

20. Awusabo Asare. Routes to HIV transmissionand intervention: an analytical framework. Health Trans Rev 1999;1-8.

21. Malungo JR. Health seeking behaviour among STD patients and institutional responses to HIV/AIDS care in Zambia. Health Trans Rev 1999;129-42.

22. Smith DJ. Premarital Sex, Procreation and HIV Risk in Nigeria. Stud Fam Plann 2004; 35:223-35.

23. UNICEF. Situation Assessment and Analysis of Children's and Women's Rights in Nigeria 2002: A Wake-up Call.

24. Caldwell P, Caldwell C, Orubuloye I. Obstacles to behavioural change to lessen the risk of AIDS/HIV infection in the African AIDS epidemic: Nigerian research. Health Trans Rev 1999;245-8.

25. Safo, M. AIDS is real. The Mirror 1993.

26. Egal F, Valstar A. HIV/AIDS and Nutrition: Helping families and communities to cope. FAO 1999. 